\title{
Comparative economics: evolution and the modern economy
}

\author{
Geerat J. Vermeij
}

Published online: 7 July 2009

(C) The Author(s) 2009. This article is published with open access at Springerlink.com

\begin{abstract}
Comparative economics - the description and underlying explanation of human and nonhuman variations on the relationship between life and its environment-seeks to discover how and to what extent the limitations that apply to some living systems can be overcome in others, including our own economy. It is founded on four phenomena, which collectively explain how life and its economic structures arise, how diversity of form and function come about, and how change occurs. These phenomena are self-organization, emergence (new properties and entities formed when parts combine), selection and adaptation, and feedback between living things and their surroundings. The systems of life vary in patterns of inheritance, the units among which selection takes place, resources, and size; these variables, in turn, affect patterns of history, adaptability, and innovation. Beneath the variation, all living systems are subject to local competition, cooperation, and evolution. Ten distinctive institutions and capacities have been thought to be unique to modern humans: cultural (non-genetic) inheritance of information and adaptations; cooperation among genetically unrelated individuals; markets in which enforceable contracts determine the quantities and prices of goods and services; utility, emergent goals and values informed by stable preferences; intentionality, deliberate action toward a predetermined goal; innovation by designing devices and institutions without historical precedents; symbolic thought; extrasomal extension, work performed beyond internal metabolism; and unsustainable exploitation of resources. These traits and capacities, which confer unprecedented power and reach, occur widely outside the human realm and have evolved independently in many organisms and ecosystems. They accelerate but do not fundamentally alter adaptation and innovation, and reduce but do not eliminate
\end{abstract}

\footnotetext{
G. J. Vermeij $(\varangle)$

Department of Geology, University of California at Davis, One Shields Avenue, Davis, CA 95616, USA

e-mail: gjvermeij@ucdavis.edu
} 
the constraints under which life in a finite world has persisted for three and a half billion years. Future civilization on Earth is therefore unlikely to forge an entirely new world order. Policies and predictions that are inconsistent with these universal realities are likely to fail. In particular: (1) local competition will remain necessary for successful adaptation and innovation; (2) an information-based economy will not replace an energy-based one, and energy use is unlikely to decline; and (3) redundancy of production in multiple sites must not be sacrificed through free trade and elimination of subsidies to achieve greater economic efficiency. Human survival requires that we work with nature, not against it.

Keywords Human economy $\cdot$ Evolution $\cdot$ Emergence $\cdot$ Intentionality $\cdot$ Market

JEL Classification $\quad \mathrm{O} 1 \cdot \mathrm{Q} 2 \cdot \mathrm{Q} 57$

\section{Introduction}

For centuries, an often tense intellectual exchange has been carried out about the place of humans and their economy in the realm of life. Some participants maintain that we are inextricably part of the biosphere, and that we and our civilization cannot escape the laws of life. Others hold that human uniqueness is so far-reaching that the principles by which the rest of the biosphere operates no longer apply to us.

If we are to place the modern human economy in the broader context of the economies of life, we need to know which aspects of a given economy are particular, or unique, and which ones are broadly applicable to all economies. In short, we need what I call comparative economics, the description and underlying explanation of human and nonhuman variations on the relationship between life and its living and nonliving environment. Living things including humans originate, grow, and change in accordance with economic and evolutionary principles that operate at every scale of inclusion from molecules to organisms, societies, and ecosystems, with humans and the modern human economy representing one extreme variation on a common theme of metabolizing life (Vermeij 1999, 2004, 2006; Corning 2005). Predictable patterns and pathways of adaptation are discernible, subject to constraints and opportunities that themselves vary in space and time. Entities that achieve greater power through competition and cooperation and higher metabolic rates disproportionately influence the distributions, adaptations, and interactions of less powerful life-forms, and therefore drive living systems (that is, economies of life) in directions of greater power and reach (Vermeij 2004).

Many philosophers, scientists, and policy-makers continue to insist that humans have advanced morally, intellectually, and technologically to the point of fashioning an entirely new world order. Not only are humans unique, but so are other life-forms, historical pathways, and environments. Keller (2007, p. 603) speaks for many with this viewpoint when she writes, 'By its very nature, life is both contingent and particular, each organism the product of eons of tinkering, of building on what had accumulated over the course of a particular evolutionary trajectory.' In this view, organisms and the lineages they represent are like individual molecules subject to Brownian motion in a 
liquid or gas. Each molecule traces a unique path, which cannot be predicted even if motions and collisions accord with established physical principles. In Popper's (1964, p. 108) words, 'the evolution of life on earth, or of human society, is an unique historical process.... Its description... is not a law, but only a singular historical statement.' For him and others (Monod 1971; Gould 2002; Corning 2005), the particulars of time, place, entities, and interactions preclude any coherent theory of history. The many unique features of humans and our civilization would, according to this perspective, make the pursuit of a unified theory even more of a lost cause.

My aim in this essay is to explore purportedly unique features of the modern human economy in the broad context of the economies of nonhuman life. Economies of life behave in predictable ways, even if their particular manifestations and the events that influence their members are unique, in the way that particles undergoing Brownian motion in a liquid are. Despite our many unique capacities and institutions, we humans conform to the laws of living nature. We cannot overcome the limitations set by metabolism in a finite world unless we expand our control to other worlds not yet inhabited by life as we know it on Earth. I begin, in Sect. 2, by outlining the four principles that in my view underlie the evolution and economics of life. I then, in Sect. 3, explore the wide diversity of economic relationships in living systems, the main point being that the modern economy is an extreme variation that nevertheless has much in common with other, nonhuman economies. In Sect. 4 on purportedly unique features of human-economic systems, I argue that few if any of these institutions or capacities are found exclusively in the human realm of economic life. In Sect. 5, I point to the harmful consequences of isolating the human-economic realm from the lessons of the rest of living nature. Finally, in Sect. 6, I provide some concluding remarks.

\section{Four fundamental phenomena}

Four interrelated phenomena collectively describe and explain how complex life and its economic structures arise and change. These are: (1) self-organization-nonliving particles spontaneously move and interact in predictable ways to create ordered states according to the properties of the particles and their surrounding medium; (2) emergence and synergy - parts act together and combine to form wholes whose properties, interactions, and effects differ from those of their components; (3) selection and adaptation-living entities competing for locally scarce resources to survive are sorted according to criteria of performance set by living and nonliving sectors of the environment; and (4) feedback-life modifies its living and nonliving surroundings, which in turn modify the performance criteria for survival. Together these four phenomena encompass a theory of economic history applicable to all systems consisting of interacting, metabolizing entities. To set the stage for the remainder of the essay, I discuss each phenomenon briefly below.

\subsection{Self-organization}

Life itself, and some of its molecular architecture, likely arose through self-organization, the establishment of ordered patterns of lifeless particles according to the physical 
and chemical properties of these particles and their surrounding medium. Mass, charge, temperature, gravity, viscosity, pressure, forces imposed by flow, and chemical concentration gradients affect the shape and stability of molecules and some simple chemical networks (Thompson 1942; Denny 1993; Corning 2005). More or less unambiguous examples of self-organization include the formation of protocells (Nisbet and Sleep 2001; Martin and Russell 2003; de Duve 2005; Chen 2006) and the arrangement of minerals and proteins in skeletal tissues (Thompson 1942). Other purported examples combine self-organization with metabolic processes created by living things. These include the movement and patterning of cells in developing embryos (Raff 1996; Carroll 2005); the locations and directions of growth of blood vessels, nerves, bones, and shells (Seilacher 1991; Vermeij 2002; Turner 2006); and the transformation of homogeneous landscapes into an ecologically patchy environment through the clustering of organisms and their metabolic activities (Rietkerk et al. 2004). Self-organization is widely credited for providing structure in cities (Krugman 1996) and the free-market system of capitalism (Rothschild 1990), as well as many other structures in the human economy (Ayres 1994; Foster 2005) and the universe generally (Kauffman 2000; Chaisson 2001).

Corning (2005) has justifiably criticized theorists for overemphasizing the role of self-organization in evolution and economics. In his view and mine, the entities that self-organize must be autonomous, and therefore interchangeable, which living things and their metabolizing parts are not. Neurons, cells, blood vessels, cities, markets, and other evolved structures that are said to self-organize have properties that have been shaped by selective processes which differ from the forces acting on inert nonliving particles. Living elements may construct wholes in accordance with such forces, but both the parts and the processes in which they are engaged are emergent phenomena with distinct functions in a living system.

\subsection{Emergence and synergy}

New properties, interactions, and effects emerge when two or more units (usually of different kinds) work together to form larger wholes. This is what happens when hydrogen and oxygen atoms combine to form water; when inorganic molecules combine and establish metabolizing networks to give rise to life (Eigen 1992; Kauffman 2000); when amino acids, catalyzed by other molecules, link to form linear sequences which in turn define proteins with complex three-dimensional structure; when cells adhere, move, and interact according to genetic 'instructions' to create a developing animal; when musical tones are organized into chords, rhythms, melodies, and entire compositions; when words are organized into sentences and stories; and when organisms band together to create complex societies and ecosystems. Even such basic notions as space, time, matter, and energy may emerge from interactions of strings or some other elementary components (Greene 2004). Emergence and synergy are necessary to create complexity at all scales of inclusion from the subatomic to the galactic (Chaisson 2001, 2005; Corning 2005). The interactions among parts always produce a vastly greater diversity of properties, structures, and effects than exists among the building blocks themselves (Kauffman 2000). 
As Corning (2005) observes, wholes have properties that influence their parts. The emergent phenomenon of function affects the fate not just of the wholes, but of their parts. Emergence is therefore not just about parts interacting to fashion wholes, but also about wholes affecting their constituents.

An emergent property to which Corning (2005) attaches great importance is synergy, defined by him as "the combined (cooperative) effects that are produced by two or more particles, elements, parts or organisms - effects that are not otherwise attainable" (Corning 2005, p. 132). It is these effects that influence the behavior of wholes and their parts.

\subsection{Selection and adaptation}

Living things vary among themselves, and not all of them are equally compatible with their surroundings. Some emergent entities are more stable, more powerful, more adaptable, or longer-lasting than others. This inequality in performance among living entities is an expression of selection, a universal, undirected process of sorting according to one or more criteria of performance. Living things metabolically convert incoming energy into the work of life-maintenance, growth, and propagation — and compete for locally scarce resources. Cooperation and other means of acquiring and retaining resources become adaptive if they enable the emergent life-forms to persist longer or to propagate more effectively than other entities. Adaptation-a better fit between life and environment - thus emerges as a universal state of living systems.

Although the type and extent of adaptation depend on the particulars of the selective regime, many (perhaps most) adaptive traits are beneficial under a wide variety of circumstances. Examples include large body size, an immune system to deal with pathogens, the ability to learn, toxicity, and armor, among many others. These traits or adaptive syndromes are expected - and observed - to arise again and again over the course of biological evolution (Conway Morris 2003; Vermeij 2006).

\subsection{Feedback}

Selection is often portrayed as a process in which entities are sorted according to criteria of performance set by their environment. Critically, however, life also affects its environment through metabolism. There is, in other words, a dynamic interaction between life and its living and nonliving surroundings (Vermeij 1999, 2004). Feedback (or mutual modification) of living entities with other entities is observable in the coordination among biochemical pathways within an organism (Kauffman 2000); the cycling of materials by organisms among the atmosphere, crust, and ocean (Fischer 1984; Rosing et al. 2006); the formation and control of neural connections by neurons in a nervous system (Kirschner and Gerhart 2005); the growth and pattern formation of metabolizing organs composed of branching tubes (Ghabrial and Karsnow 2006); price-setting in markets (Jacobs 2000); and escalation (or, in special cases, reciprocal coevolution) between prey and predator, plant and pollinator, parasite and host, and competing companies or nation-states (Vermeij 2004). The two-way effects of living things and their surroundings are essential to the emergence and selection of workable, 
well-adapted wholes built of interacting components that combine in multiple ways according to a few simple rules (Sterrer 1992; Vermeij 2004). They are thus basic to all economic activity.

This formulation of the basis of economic systems and evolution differs somewhat from conventional treatments. Whereas many evolutionary biologists view selection as a creative process that reigns supreme among the mechanisms of evolution, I argue that an adequate theory must account not only for which entities succeed and which do not, but also for how those entities that undergo selection arise in the first place (see also Vermeij 2004; Corning 2005; Turner 2006; Lynch 2007; Reid 2007). For Fontana and Buss (1994, p. 761) note, 'Selection cannot set in until there are entities to select.' Selection has a role in stabilizing and integrating functional entities; but self-organization, emergence, and feedback are also necessary for the formation of diverse living wholes.

\subsection{The economy}

The pathways and transformations of matter and energy in a living system describe that system's economy. Members of the economy compete, cooperate, produce, consume, and trade. Competition and environmental heterogeneity-the latter often being the product of the economy itself_create diversity (Smith 1776; Vermeij 2005).

Although the criteria for survival vary greatly in their particular manifestations, all aspects of an economy are measurable in units of energy or power. Resources, benefits, costs, investment, price, and money can be expressed in units of energy, which is stored for later use of expended in biological or economic work. Rates of production or consumption, ecological productivity (the rate of biomass production per unit time), economic profit, metabolic rate, growth rate, and the rate of evolution are expressible in units of power (Lotka 1922; Van Valen 1976; Brown 1995; Vermeij 2004). Economic inequality among members is best expressed as a dimensionless ratio between either the energy or the power of entities.

This dimensional approach to comparative economics will strike some as simplistic. Although water, oil, and food are all commodities that can be expressed in units of energy, they are not interchangeable. Energy and matter come in many forms, not all of which are relevant to any given economy. Although I acknowledge this diversity, I believe it is useful to think of commodities and processes in dimensional terms, much as it is useful to apply to common dimensional framework to phenomena in chemistry and physics.

\subsection{The materialist perspective}

This materialist conception contrasts with a worldview emphasizing thermodynamics and information content of systems. Theorists who perceive evolution and economic life as a struggle for information point to the genetic code - the linear sequence of bases on RNA or DNA molecules that specify sequences of amino acids in proteinsas the information-based means by which life propagates. They correctly point out that metabolism enables life to exist in a state far from thermodynamic equilibrium and that 
work of metabolism creates an organizational or informational order (Kornacker 1968; Morowitz 1968; Riedl 1978; Wiley and Brooks 1982; Brooks et al. 1989; Weber et al. 1989; Ayres 1994; Kauffman 2000; Chaisson 2001). Foster (2005, p. 368), for example, asserts that culture 'constitutes a form of organized complexity in shared knowledge, absent at the chemical and biological level of enquiry.' In the modern 'knowledge economy' (Mokyr 2002), 'knowledge... is both a means and an end' (Hodgson 1999, p. 262).

Although this approach is technically correct, I find it too far removed from the lives of the entities among which emergence, selection, and feedback take place. Without the material survival machine that is the living organism, information-whether it be genetic, epigenetic, or cultural-is meaningless. The information that truly mattersliterally a matter of life and death, success and failure, prosperity and poverty-is adaptation. As Sterrer (1992) and I see it, an adapted organism or system is a living hypothesis of its environment, a hypothesis that is continually tested and modified by selection and feedback according to circumstance.

\section{Variations on a theme}

The systems of life vary greatly in the phenomenology and realization of patterns of inheritance, the units among which selection takes place, resources, and size. These variables, in turn, affect patterns of history, adaptability, and innovation. Diversity within and among systems arises because components can combine in multiple ways and because the conditions under which life thrives vary according to the constraints and opportunities to which living things are exposed (Vermeij 2004). Comparative economics accounts for these variations and seeks criteria by which diverse systems can be compared. Perhaps most importantly, its goal is to discover how and to what extent the limitations that apply to some systems can be overcome in others, including our own advanced economy.

\subsection{Patterns of inheritance}

Some systems, especially those prevailing on the early Earth, are downright unfamiliar to most contemporary observers. A growing consensus holds that the earliest life-forms comprised a community of dispersed protocells-replicating molecules surrounded by a membrane-whose chemical reactions are driven by external sources of energy (Nisbet and Sleep 2001; Martin and Russell 2003; de Duve 2005; Chen 2006). The molecular sequences that specify the machinery of metabolism and that allow innovations and adaptations to spread by selection were contained not in single individuals, but collectively in the community of protocells (Woese 1998; Vetsigian et al. 2006). Traits affecting survival and propagation were transmitted horizontally through interactions between protocells and vertically by replication. Only when the coding system became stable and essentially universal as a result of selection [or, to use Arthur's (1989) term, lock-in] did the familiar vertical transmission become the dominant mode of inheritance (Woese 1998; Vetsigian et al. 2006). 
Although vertical inheritance is the norm in the evolution of 'higher' organismsplants, animals, and fungi-genes and nongenetic information also flow horizontally. Viruses and bacteria aid in the lateral spread of genes among species, and in fact provide the basis for much of the genetic engineering that characterizes modern biotechnology. Sex, which involves a highly regulated recombination of genes between male and female to produce offspring whose genetic makeup differs from that of either parent, is a form of horizontal gene transfer within species. Hybridization between members of separate species is widespread and often results in the formation of new species in both plants and animals (Mallet 2007). Well-integrated symbioses of phylogenetically distant component organisms have produced new organisms such as lichens, corals, wood-digesting termites, nitrogen-fixing land plants, rooted vascular plants, and the eukaryotic cell.

Adaptive evolutionary change can occur regardless of how traits are inherited and modified (Mesoudi et al. 2004; Vermeij 2004). The different modes of inheritance do, however, have important implications for history, adaptability, and innovation.

\subsubsection{History}

Evolution is typically portrayed as a process of tinkering: most modifications on established themes appear through point mutations or other small genetic changes, and accumulate through time, leaving a phylogenetic record as they do so. If it weren't for vertical transmission, we would be unable to piece together genealogies or trace evolutionary lineages through time. The very notion of a lineage depends on vertical transmission and therefore on evolutionary tinkering. Horizontal transmission wipes away some of this history, and transforms the ideal of an evolutionary tree with open branching into a more complex structure in which some of the branches form an interconnected network. In fact, as also noted by Doolittle and Bapteste (2007), the classic tree of life is only one of several patterns that we observe in the history of life; networks and webs, reflecting horizontal patterns of inheritance, occur alongside the branching trees as classically conceived by Darwin (1859).

\subsubsection{Adaptability}

Vertically transmitted genetic adaptations tend to be well regulated and stably expressed, but their rate of change is limited by generation time, the interval between an entity's birth and age of first reproduction. The speed and flexibility of adaptive responses are faster when vertical inheritance is coupled with other mechanisms by which traits spread. Experiments with sexual and asexual strains of yeast, for example, show that sexual recombination speeds up the rate at which these fungi can adapt (Goddard et al. 2005). Moreover, sex and the other mechanisms discussed above produce a greater diversity available for selective agents to act on. The variety and frequency of potentially life-altering circumstances that an individual confronts-fluctuations in resources and weather, and enemies of all kinds-cannot be accommodated by the genetic system without the generation of variety by other means. A vertically inherited instructive and regulatory set of genes thus spawns a huge, flexible array of neural, immunological, and epigenetic responses to meet spatially and temporally 
unpredictable variations in the environment (Frank 1996; Kirschner and Gerhart 1998, 2005; Carroll 2005).

Modifications in growth, shape, size, and behavior resulting from immediate responses of an organism to its environment are met with everywhere in biology. In multicellular organisms, the course of development from fertilized egg to adult incorporates a great deal of so-called epigenetic information, which comes about through the interaction of structural genes and regulatory genes (Wilson et al. 1974; Raff 1996; Newman and Müller 2001; Carroll 2005; Kirschner and Gerhart 2005). In fact, many aspects of shape now under strong genetic control, such as the consistent right-handedness of claws in some crab species and the right-handed shell coiling characteristic of most snails, likely originated as nongenetic phenotypic reactions to factors in the environment or the organism's internal architecture. Regulation and stabilization of these traits by genes through a process of genetic assimilation evolved because these initially unregulated responses were consistently beneficial (Waddington 1962; Agrawal 2001; Pigliucci 2001; Palmer 2004). Similar mechanisms are at work in initially nongenetic behavioral traits. In many animal species, mates observing the mating of other members of the same species may mimic the preferences of those mates, with the result that patterns of preference become vertically transmitted. Song dialects in birds and linguistic dialects in humans undergo a comparable transformation from horizontal to vertical transmission (Danchin et al. 2004).

\subsubsection{Innovation}

Innovation in both the natural and human realms arises in most cases either nongenetically or through horizontal recombination of genetic elements from different lineages. Lateral transfer between genetically distinct entities is responsible for almost all biochemical innovations, including complex synthetic and metabolic pathways (Vetsigian et al. 2006). Compound organisms consisting of symbiotic components from separate lineages have emergent novel traits not possessed by any of the partners (Margulis 1991). Gene duplication, which may often originate from hybridization between species (Mallet 2007), likewise has spawned many innovations by increasing degrees of freedom and loosening constraints on directions of adaptation (Raff 1996; Carroll 2005; Kirschner and Gerhart 2005).

\subsection{Units of selection}

There is great diversity, both among and within economic systems, in the types of entities that are subject to selection and in which adaptation can be said to be present. In traditional conceptions of evolution, the individual organism is seen as the primary unit of evolution and adaptation (Williams 1966; Leigh 1983; Corning 2005). The criteria for entities as units of evolution - the ability to multiply, inheritance of traits, and variation in these traits among individuals - do indeed qualify organisms as evolutionary units (Maynard Smith 1991). These same criteria, however, also describe other entities and systems, including coalitions, species, coherent societies, languages, cultures, and even some ecosystems (Wilson 1974, 2002, 2003; Stanley 1975; Eldredge 
1985; Leigh and Rowell 1995; Sober and Wilson 1998; Gould 2002; Leigh and Vermeij 2002; Danchin et al. 2004; Mesoudi et al. 2004). An entity becomes individual-like, and therefore subject to selection and adaptation, when the rate of change among its components is less than the rate of sorting among like entities, that is, when the whole is intact long enough not to dissolve into chaos (Kauffman 1993). Higher-order units of biological evolution emerge when their self-interested components come under sufficient regulation by the whole's central authority to favor the community good over the short-term selfish behavior of the living parts (Leigh 1983; Buss 1987). Ecosystems composed of dispersed living things can be thought of as economically evolving units in the sense that their emergent properties - diversity, resilience, primary productivity, extent of facilitation, rates of consumption, and rates of recycling nutrients, among others-become stable attributes that affect the systems' persistence and replicability.

\subsection{Resources}

History reveals that, as increasingly inclusive entities become individual-like and as new properties emerge, the list of potentially limiting resources expands (Vermeij 2004). For example, with the emergence of sexual recombination about 1.5 billion years ago, the species became an evolutionarily significant unit, both in a phylogenetic sense as a genetically independent branch on which gene exchange among organisms maintains cohesive populations, and ecologically as a group of individuals constructing and occupying a collective 'niche' comprising resources, habitats, ways of life, allies, and enemies. Mates became a locally limiting resource for which females or males could compete in those species in which internal fertilization evolved, spawning not only extraordinary bouts of sexual selection but also producing large numbers of species (West-Eberhard 1983). Social organization in animals-usually an adaptation to enhance competitive ability and to counter predators (Wilson and Hölldobler 2005) — enables individuals to compete for rare positions of high status (Rosen 2005). Light became a meaningful resource only when photosynthesis arose. Nest sites safe from predators were unnecessary before predators capable of consuming multicellular animals evolved some 550 million years ago. Pollinators capable of moving among dispersed plants became locally limiting resources when land plants evolved mechanisms that no longer depended on wind or water to bring male and female gametes together. Fossil fuel meant nothing to any organism until modern humans began to use peat, coal, and petroleum. Businesses compete for customers, cities compete for businesses. Ultimately, these emergent resources for which entities compete are new, even if those resources are composed of components that were objects of selection for less derived entities.

\subsection{Size}

Great diversity also exists among systems that differ in size. Expansive ecosystems such as those on continents and in large bodies of water tend to support more species, to be more productive, and to show greater degrees of escalation between species and their enemies than do small systems on islands or in island-like habitats. Only 
large ecosystems can support large, metabolically active top predators and large, fastgrowing, competitively dominant plants (Vermeij 2004). Parallel variations occur in human societies: small human groups support fewer occupations, less specialization, and a less hierarchical structure than large ones (Diamond 1997) and, as in the natural world, cannot take advantage of economies of scale. Comparisons between human and nonhuman economies must therefore take size into account. In particular, the large (indeed global) modern human economy should be compared to large present or past ecosystems on continents and in oceans.

\subsection{Summary of economic variation}

Three points emerge from these comparisons. First, economic systems exhibit variation in the mechanisms by which traits are introduced and propagated, in the entities among which selective processes operate, and in the resources for which entities compete. Second, these variations coexist; some systems arose earlier than others, but examples of all of them can be found in today's biosphere. Third, the natural systems with which economists are most apt to compare the human economy are highly derived, and represent a small fraction of the diversity of systems that have persisted for eons. Comparisons between human and nonhuman economies should therefore encompass a much greater range of the observed variation. Precise equivalents of interactions, units, resources, information-transfer mechanisms, and other properties will not always exist and should not be expected. Rather than looking in vain for such precise correspondences, we should look for universal properties, determine whether and how these added levels of complexity affect economic systems, and ascertain whether, how, and to what extent our own highly modified economy violates the laws of life.

\section{Unique features of the human economy}

Humans and the institutions they construct are distinctive in so many ways that they are often thought to conform to rules radically different from the principles governing the rest of living nature. Some of these traits pertain to the physical characteristics or life-history of individuals: a large brain, very long pre-reproductive period of development, long lifespan, upright posture, the ability to run long distances, a relatively hairless skin, and deep insertion of the tongue in the oral cavity (Carey and Judge 2001; Aiello and Wells 2002; Kaplan and Robson 2002; Bramble and Lieberman 2004; Jablonski 2004). Although these traits cannot be separated from the economic, social, and mental characteristics with which I am chiefly concerned, they will not be explicitly treated here.

Other purportedly unique traits reflect social and mental capacities. I classify these, somewhat arbitrarily, under 10 headings: (1) cultural transmission of information; (2) cooperation among genetically unrelated individuals; (3) markets, where enforceable contracts between traders determine the quantities and prices of goods and services; (4) utility, emergent goals and values in life, such as wealth and happiness, informed by stable preferences; (5) intentionality, the directed, deliberate actions 
toward a predetermined outcome; (6) innovation by designing devices and institutions without historical precedents; (7) symbolic thought, intimately connected with language and the development of rules governing economic and social institutions; (8) declining birth rates in modern societies; (9) extrasomal extension, work performed beyond internal metabolism; and (10) unsustainable exploitation of resources.

\subsection{Culture}

The transmission and accumulation of knowledge, myths, music, laws, and material possessions (including societal ones) by cultural rather than genetic means is so prominent in our social species that it sets humans apart from the rest of life. As noted above, cultural transmission confers adaptability, the ability to respond rapidly to challenges and opportunities, and above all the accumulation of collective adaptations and resources. All nine other attributes discussed below are intimately connected to culture. Indisputable as all this is, cultural inheritance neither invalidates the reality of evolution nor such phenomena as feedback, emergence, competition, and inequality that characterize life and its interactions with its surroundings.

\subsection{Cooperation}

All living things are ultimately built of cooperating components, but in no single species does cooperation — or mutual help-extend as widely as it does in humans. In humans, genetically unrelated individuals help one another in ways that often appear to involve personal sacrifice. Key elements in the evolution and maintenance of this cooperation among individuals who are not kin include rewards for cooperators, punishment for those who do not cooperate, and a link between cooperativity and reputation (Milinski et al. 2002; Wilson 2002; Fehr and Fischbacher 2003; Fehr 2004; Panchanathan and Boyd 2004; Cassill 2006; Henrich et al. 2006; Nowak 2006; Hauert et al. 2007). The advantages of belonging to a cohesive, competitively superior group bound together by patriotism, religion, or a common ethical code outweigh the potential individual sacrifices (Landa 1976, 1981, 1999); and it is selection among cohesive groups that strongly favors individual cooperation (Wilson 2002; Wilson and Hölldobler 2005; Cassill 2006).

The establishment of impersonal exchange among strangers is fundamental to the emergence and success of human-style trading in markets. Institutions such as banks, patents, formalized and tradable property rights, legal contracts, and a judicial system of laws and their enforcement provide a measure of economic security for people who often do not know each other and who may not belong to the same cohesive group. Such institutions make long-distance trade in large economies possible and reduce the risks of investment through breach of contract. Greater protection against cheating is made possible by these arrangements, and enables inventors and entrepreneurs to transform new ideas into marketable goods and services (Landa 1976; Mokyr 1990; Ofek 2001; Seabright 2004). In smaller economies or in certain special cases, a common code of conduct enforced in a unified, often genetically or linguistically homogeneous group of middlemen - specialized traders who facilitate exchange between buyer and 
seller-may substitute for the more formal, more impersonal institutions that characterize large modern economies (Landa 1981, 1999). Such a code of conduct, or informal mutual understanding based on frequent interactions among the same people, exists among genetically/ethnically homogeneous Chinese merchants in Southeast Asian societies (Landa 1981, 1999) as well as the Jewish and Italian merchants in Medieval Europe (Landa 2008). Like the formal mechanisms in larger economies, these arrangements depend on trust, and reduce the risks inherent in exchange between individuals whose interests do not always coincide. The homogeneous middleman groups exemplify a high level of cooperation among people operating in economies where formal law for the protection of property rights and contracts is not well-developed.

Government is the social institution that in advanced human societies makes and enforces many of the rules that enhance individual and collective economic security. Although this institution may be unique to humans (Rothschild 1990), dominance hierarchies (and therefore the dominant male or female) perform analogous functions in numerous animal species (Corning 2005), and can therefore be said to be a simple form of government.

In nature, cooperation among unrelated entities is widespread. Recent work in Uganda shows that, although kinship lays a role in many observed instances of cooperation among male chimpanzees, most cooperative acts take place between unrelated individuals (Langergraber et al. 2007). In species of fish that form schools, unrelated individuals of the same species that belong to a school both contribute to and benefit from the antipredator defense and hydrodynamic advantages provided by the group, and have no incentive to defect (Landa 1998). Cooperation among phylogenetically distant individuals is known from thousands of examples. Plant and animal cells, for example, are the product of far-reaching cooperation and integration among components-mitochondria, plastids, nucleus, and other structures-whose ancestors were independent, phylogenetically distant organisms. The symbiosis produced a new, competitively superior whole, much as cooperation and trust in human societies enhance societal vigor. The controls that regulate multiplication and limit competition among the parts do not arise from the kinds of deliberate regulation that characterize modern human societies, but their effects are similar.

\subsection{Markets}

Many economists and biologists believe that the market, involving the voluntary exchange of goods and services between strangers, and made possible by formal rules or informal codes of conduct, is a unique invention of modern humans (Hirshleifer 1977; Tschirhart 2003; Seabright 2004; Mokyr 2006). In Ofek's (2001, p. 1) words, 'The propensity and capacity to exchange one thing for another between two traders - however unrelated to each other-is a profound distinguishing feature of human subsistence.' Unlike nonhuman animals, which hold territory and other possessions transiently, people in advanced economies have developed elaborate systems of property rights encoded in a welter of laws and rules, which facilitate the trading of goods and services in the marketplace, often by specialized middlemen, using money or guaranteed notes as the means of exchange (Landa 1976; Noë and Hammerstein 
1996; de Soto 2000; Bowles and Hammerstein 2003; Pryor 2003). What a buyer is willing to buy, and a seller is willing to sell, is determined by price, an amount of money that reflects the information that the parties involved in the trade know or communicate about supply and demand (Hodgson 2001; Bowles and Hammerstein 2003). At least in theory, this price-setting mechanism works because both supply of, and demand for, a given commodity are under the complete control of producers and consumers of that commodity, and because information about supply and demand is complete as well as reliable. In practice, of course, information is never complete, and traders with more power disproportionately influence (and often distort) price.

In natural systems, by contrast, exchange is involuntary, middlemen and money are absent, there are no enforceable contracts, and factors beyond the control of members of the economy affect supply and demand. In Ofek's (2001, p. 9) view, 'Exchange, or apparent exchange, among living organisms other than humans is largely confined to the realms of symbiosis and nepotism (i.e., transfers among members of separate species and transfers among related conspecifics, respectively).'

Two questions emerge. First, are the traits that determine human-economic markets truly without precedent in nature? Second, are human-economic markets so radically different that the economic interactions of nature are irrelevant or even misleading for understanding our economic system? Put differently, do human-economic markets and other institutions break the laws governing organized nonhuman life, or do they extend and modify prevailing rules?

The answer to the first question is 'no.' Consider the role of enforceable contracts. Enforcement occurs through a system of punishments and rewards (Henrich et al. 2006). Studies of mutually beneficial relationships in nature reveal that sanctions play an important role in the origin and maintenance of these cooperative arrangements between unrelated parties. In the symbiosis between leguminous plants (such as peas) and the nitrogen-fixing bacteria that invade and occupy nodules on the roots of these plants, the host plant can deny the bacteria oxygen if the bacteria fail to deliver nitrogen to it, resulting in a sharp decrease in the reproductive success of the bacteria (Kiers et al. 2003). In societies of social insects including some bees and ants, workers are capable of laying eggs but are prevented from doing so by nestmates. This kind of policing thus reduces selfishness and enforces altruism by the workers toward the queen (Renseleers and Ratnieks 2006). These sanctions may not look like the mechanisms operating in the human-economic marketplace of today, but they have the same effect of facilitating cooperation and trade. Mutualisms are always subject to dissolution by selfish cheaters, and remain intact only when evolved controls and regulations are in place (Buss 1987; Thompson and Cunningham 2002). This is as true in nature as it is in the human realm. Government, enforced taxation (or redistribution of resources), and other ostensibly uniquely human institutions exist in nature in many evolved relationships if not by name (see Sect. 5.3 below).

As to the second question-whether human-economic markets break the laws of organized nonhuman life-I believe the answer is a qualified 'no.' By the various institutions that we have evolved culturally over the centuries, markets have become ever larger, and trade is carried on by entities that are usually far removed from each other. This evolution represents an enormous scaling up of economic exchange, and all but eliminates the ideal for some that individual societies can be self-sufficient. 
But trends toward globalization are not unique to the human economy. With the evolution of highly mobile animals capable of directed, long-distance migrations or of less directed, passive dispersal, remote ecosystems that would have had no contact whatsoever became economically joined, often exchanging resources via animal vectors. Birds migrating between northern forests and the tropics, or between the north and south polar regions, use nutrients obtained in one region to subsidize life in the other, and vice versa. This kind of mutual subsidy, or long-distance trade, would have been impossible before warm-blooded birds took to the skies during the Cretaceous period (Vermeij 2004). Market institutions are, of course, absent in this situation, but the effects of increasing the magnitude and spatial scale of exchange of resources - of goods and services-is not so different from the increase in trade that refinements to market-related economic institutions brought. Markets, money, and middlemen surely facilitate trade, but they do not fundamentally alter the economic rules that emerged very early in the history of life.

\subsection{Utility}

At the heart of economic theory and practice in the human realm is the idea that humans and their societies develop stable tastes and preferences, which determine economic decisions. In Becker's (1976, p. 14) somewhat idealistic conception, 'all human behavior can be viewed as involving participants who maximize their utility from a stable set of preferences and accumulate an optimal amount of information and other inputs in a variety of markets.' These preferences reflect goals that other life-forms are thought not to have: health, happiness, affluence, influence, reputation, and the like. For Mokyr (2006, p. 1011), 'economies are not like ecologies in that the main purpose of life seems to be life itself.... There is no real analog in biology to the economist's concept of utility.'

Reality is, I think, considerably more nuanced. Rather than indicating a sharp break between a rich human life of purpose, tastes, and preferences and a poor nonhuman existence with only survival and reproduction as a basis for meaning, I perceive a continuum. In the beginning, life was an 'impersonal, unreflective, robotic, mindless little scrap of molecular machinery' (Dennett 1995, p. 203). With the evolution and elaboration of nervous systems and social organization, some animal lineages became increasingly endowed with emergent emotions, meaning, purpose, and intentional preferences for happiness, wealth, leisure, status, honor, peace, reputation, arousal, dignity, and pleasure. In our social species, shared culture-music, religion, fashion, and the pursuit of knowledge-provides the context in which these diverse forms of utility flourished (Wilson 2002; Mithen 2006). It is true that 'Emotions and their expression are at the very centre of human life and thought...' (Mithen 2006, p. 98); but emotional states such as happiness, fear, shame, caring for others, desire for mates, and curiosity - all key elements that enrich mere existence with emergent utilityare very widespread, especially in mammals (primates, carnivorans, and cetaceans) and birds (parrots and many songbirds) (de Waal 1996, 2001; Butler and Cotterill 2006). Individual and social values influence what we buy and sell, how we conduct our lives, and how we interact with others; but conscious preferences do not differ 
fundamentally from the imperatives of survival and reproduction that inform the behavior and economic 'decisions' of nonhuman life. In fact, as Corning (2005) points out, purposiveness (or teleonomy) informs the behavior of many organisms, and can be traced back very far in evolutionary history. There can be little doubt that humans have gone further than other species in adding dimensions of want and meaning, largely arising from our far-reaching sociality, but we are at the end of a continuum, not at one side of a chasm.

\subsection{Intentionality}

No attribute of humans has received more attention as the source of our uniqueness than intentionality, the ability to anticipate, create, and modify outcomes by specific, directed, action. North (2005, p. viii) puts the case succinctly: 'In contrast to Darwinian evolutionary theory, the key to human evolutionary change is the intentionality of the players....Human evolution is guided by the perceptions of the players; choicesdecisions - are made in the light of those perceptions with the intent of producing outcomes downstream that will reduce uncertainty...in pursuit of their goals.' For Mokyr (2006, p. 1009), intentionality is all about how we adapt to and modify our surroundings for our own benefit: 'human technology is the result of knowledge, that is, the conscious realization that there are regularities in nature that can be exploited. No such consciousness exists in nature...'

As with utility, the gulf between intentional, conscious, strategy-forming humans and automaton-like nonhuman life envisioned by these economists implies a qualitative gap, a conspicuous break from the yoke of our evolutionary past. But is this gap real, and does it truly represent liberation from the rules of biological adaptation?

I think not. Darwin (1859) chose the breeding of domesticated species by humans as a good model for selection in the wild even though domestication involves directed, intentional choices with a particular desired goal in mind, whereas natural selection is imposed by current agents and agencies without expectations or hopes for the future. Directed selection is faster than at least some forms of natural selection, and may favor traits that selection in the wild did not; but natural agents of selection vary hugely in the pattern of selection they impose and in the traits that their actions cause to be favored. Over the course of time, the direction of evolution may change as circumstances change, whether the lineage is wild or under human domestication. Intentional behavior permits economic life to become more complex (Arthur 1999); it makes us adaptively more flexible, increases our rate of cultural adaptation, and allows us to harness external sources of energy to gain enormous per-capita and collective power (Vermeij 2004). Utility in the economist's sense consists of criteria by which we make decisions and measure our performance. Selective agencies in the wild similarly set criteria for which adaptations work and which traits do not. Selection remains selection, regardless of who the agents are, which criteria distinguish success from failure, or how inclusive the units are among which selection acts (see also Hodgson 2002).

In any case, intentionality may be better developed in humans than in other animals, but it is not unique to us. Warm-blooded birds and non-human mammals exhibit a range of conscious, intentional behaviors, indicating that our ability to predict and 
manipulate our surroundings by deliberate action is linked to the repertoires of other animals by a smoothly graded series of intermediate states of intentionality. Most important of all, perhaps, is the observation that advanced levels of intentional behavior, such as those seen in parrots, jays, and crows (Butler and Cotterill 2006; Raby et al. 2007), have evolved in birds, a group of vertebrates that has been phylogenetically separate from the line leading to mammals for some 300 million years. The independent acquisition of intentional behavior and its material neural basis in several animal groups testify to the broadly applicable benefits of these powers and to a certain predictability of their evolution (Vermeij 2006).

\subsection{Innovation}

Dennett (1995) has suggested that humans innovate in ways that nonhuman biological systems do not. In his view, human foresight makes possible the design of tools, machines, buildings, industrial processes, and any number of other material and intellectual innovations. In their construction, these devices need not be functional at every stage, because these devices are, in effect, exposed to selection only when complete. Dennett (1995) contrasted human artifacts with organisms, which must be 'going concerns' at every stage of development and during all evolutionary transitions. We construct things not by trial and error, as the biological processes underlying evolution do, but by formulating and testing hypotheses. In other words, we employ knowledge and logic in designing and producing our inanimate infrastructure, which need have no historical links to any ancestral versions (Dennett 1995; see also Rothschild 1990).

But this kind of human engineering has much in common with combinatorial innovation in biological development and evolution. Enzymes, structural proteins, biochemical pathways, immune systems, nervous systems, cells, animal and plant bodies, societies and ecosystems are built of parts-modules, compartments, and circuitswhich through weak connections come together and interact in myriad, flexible ways according to a few basic rules (Raff 1996; Kirschner and Gerhart 1998, 2005; Carroll 2005). As put succinctly by Kirschner and Gerhart (2005, p. 199), 'Biology developed in the direction of linking together simple circuits, rather than making the individual circuits more complex.' Through a variety of mechanisms including redundancy of genes, flexible linkages between parts, and cooption of the same genes for different functions in different genetic and physiological environments, organisms generate and accumulate a great deal of exploratory variation, much of it initially protected from immediate elimination by being nonlethal (Kirschner and Gerhart 1998, 2005). This exploratory variation, moreover, is not random, nor is it a strictly trial-and-error sampling of a nearly infinite variety of possibilities. Instead, it comprises states that slightly modify existing phenotypes in nonlethal ways (Eigen 1992; Kirschner and Gerhart 1998, 2005).

In short, biological and economic systems have evolved toward an organizational structure that encompasses, tolerates, generates, and accumulates variation (Kirschner and Gerhart 1998, 2005). This structure is rendered flexible in that the component modules interact loosely with other modules while retaining a certain degree of autonomy. Not only do systems with such a structure permit innovations to arise and to 
be incorporated, but they become robust in the face of many externally or internally imposed shocks. For example, Krugman (1996) and Porter (1998) noted that cities or other 'economic clusters' built around enterprises engaged in particular economic pursuits become productive, competitive, and innovative when the enterprises are loosely linked through local relationships in a flexible network. The most robust ecosystems can tolerate and incorporate new species and adjust to the disappearance of others.

As in the other comparisons I have discussed, the highly derived human-engineering method of design and construction described by Dennett (1995) and the organization of cities and economic clusters emphasized by Krugman (1996) and Porter (1998) are connected to the less intentional systems of biology through intermediate states. Early hominids emphasized unitary construction when fashioning tools or using voice tones. Utterances and manufactured objects were therefore independent units rather than modular in their construction, as is the case in most other animals. Compound tools, compositional languages and music, and the emergence of symbolic thought appear to be the hallmarks of modern humans beginning in the Late Paleolithic, perhaps by 60,000 or 70,000 years ago or even later (Ambrose 2001; Weaver 2005; Mithen 2006). The transition from unitary to compositional cultural entities and artifacts thus resembles the evolution of nonhuman embryos, societies, and ecosystems. In both the human and natural realms, combinatorial innovations are more easily generated and accommodated as the underlying organization becomes more modular, redundant, and flexible.

\subsection{Symbolic thought}

As noted above, the use of sounds (and later writing) as representations and symbols of facts and emotions is a salient distinguishing characteristic of humans. Language and writing are combinatorial codes that allow individuals to communicate over wide distances, to transmit complex instructions and observations far into the future, and above all to create a collective pool of information far exceeding the knowledge that any single individual can master. At least in principle, individuals can learn from this accumulated store, and therefore avoid the costly trial-and-error style of learning that is supposed to characterize nonhuman animals (Castro and Toro 2004).

Given its central role in communication, symbolic thought and language fundamentally reflect our social organization, and may well be responsible for making larger social groups possible. Music, language, and religion are powerful, socially evolved means to create bonds among unrelated individuals and to give resulting groups coherence and collective power (Vermeij 2004; Mithen 2006). Writing is, of course, central to organized economic activity by remote actors (Rothschild 1990; Wilson 2003). Telecommunication and computers have vastly expanded every aspect of human-economic life by extending the reach, reducing the cost, and increasing the quantity of information.

\subsection{Declining birth rate}

Another potentially unique human behavior, evident only in some advanced civilizations, is the voluntary per-capita decline in birth rate (Mokyr 2006). This 
decline, which began in France and the United States during the late eighteenth century (Cohen 1995), would seem to violate the evolutionary principle that, as the supply of resources rises, fecundity should increase. In the human case, many factors made the decline possible or contributed to its spread. These include: (1) a more reliable food supply, leading both to fewer famines (Cohen 1995; Landes 1998) and more importantly to an increase in per-capita caloric intake and thus worker output (Fogel 1994); (2) enhanced sanitation, public health, and disease-fighting medicines, leading to smaller epidemics and reducing chronic inflammation (Cohen 1995; Landes 1998; Carey and Judge 2001; Finch and Crimmins 2004); and (3) reduction in poverty through social spending (Lindert 2004). Social spending in particular reduced the cost of reproduction for women by broadening the costs and responsibilities of raising children (Carey and Judge 2001; Penn 2003). Through a series of positive feedbacks involving rates of reduced rates of juvenile mortality and increased per-capita investment on children in order to make offspring more competitive, reproductive effort shifted from high fecundity to lower fecundity coupled with higher survival (Carey and Judge 2001; Kaplan and Robson 2002). The cost of children forgone was more than offset by the gain of offspring survival during this fertility transition. Birth control, imposed from above by governments or embraced voluntarily by individual women, has further allowed society as a whole to invest more resources in the next generation.

Tradeoffs between survival and fecundity are extremely widespread among organisms. As a result, selection has favored long life and reduced per-capita fertility in many species besides modern humans (Carey and Judge 2001; Kaplan and Robson 2002). Highly effective protection against predators appears to be a key mechanism for tilting selection toward greater per-capita investment in offspring. Life in trees (parrots, early primates), powered flight (bats and birds), and social protection of reproductive females by worker castes (many social insects) have all been cited as antipredatory adaptations by metabolically active, long-lived animals with relatively low rates of production of fertile offspring and high investment in the survival of individual young (Wilson 1971; Ricklefs 1979; Keller and Genoud 1997; Dudley 2000; Carey and Judge 2001; Kaplan and Robson 2002; Cassill 2006). A parallel development in plants is discernible when the maternal investment in the endosperm of flowering plants is compared to the near absence of such investment in more ancient groups of land plants (Westoby and Rice 1982; Bateman and DiMichele 1994).

\subsection{Extrasomal extensions}

Most of the energy that powers human civilization today does not come from food but from outside sources that enable us to perform work beyond our internal metabolism. We use wind, water, Earth's interior heat, and fuels derived from living plants, animal dung, fossils, and nuclear reactions. Domesticated animals work for us in agriculture and transport. No other species or ecosystem comes close to the diversity of energy sources we harness, or to the per-capita and collective power of our economic activity (Boyden 1987; Mokyr 1990; Cohen 1995; Marden and Allen 2002). More than any other living entity, we employ extensions of our bodies-tools, weapons, buildings, vehicles, foot wear, clothes, roads, ports, dams, reservoirs, farms, factories, cooking 
utensils, computers, and so on-to exert power and control over our surroundings. This extrasomal expansion, made possible by the eight previously discussed human capacities, constitutes the material basis for our ecological dominance.

Our unprecedented reliance on extrasomal matter and energy does not, however, represent a radical departure from what organisms have been doing all along. The harvesting of light through photosynthesis may have tripled the energy available to life during the very early stages of life on Earth (Rosing et al. 2006). Living things have constructed or used an enormous variety of extensions of their bodies that enhance nutrition, defense, and reproduction. Examples include soil, burrows, reef frameworks, nests, beehives, termite mounds, shells, tubes, cocoons, galls, beaver dams, and a wide variety of 'domesticated' organisms. Tool-use by some large-brained birds and primates, though primitive by our standards, demonstrates that deliberate modification of devices to perform specific functions evolved multiple times (Butler and Cotterill 2006).

\subsection{Unsustainability}

Although many economists believe that human-economic growth can be sustained more or less indefinitely thanks to new resources substituting for depleted ones and to technological advances fueled by the 'knowledge economy', others point out that the human stamp on Earth's biosphere has become so large that only the most intrusive interventions can save us from irreversible collapse. It is not my intention to revisit the argument for unsustainability that others have made so well (Boyden 1987; Perlin 1989; Penn 2003; Diamond 2005) except to note that unsustainable exploitation of resources has characterized many human societies beginning as early as 45,000 years ago, when the first wave of human-caused extinctions devastated the Australian megafauna. Instead, I shall consider the claim (Sterrer 1993) that, within the realm of life, economic unsustainability is unique to the modern human species.

The overwhelming public perception of the natural world is captured by the phrase 'balance of nature'; ecosystems are at equilibrium and sustainable in the long run in the absence of human interference. Forests, mudflats, grasslands, reefs, and a host of other natural systems do indeed achieve considerable stability and robustness in the face of disruptions. Resources are recycled and populations are held in check by a variety of diffusely and unintentionally introduced regulatory mechanisms.

Nevertheless, recycling and retention are not $100 \%$ effective. Wardle et al. (2004), for example, have shown that all six tropical and temperate forest ecosystems they studied inexorably deplete nutrients from the soils on which the forests depend, with the result that late-stage vegetations have low productivity and are stunted in appearance. Only when nutrients are replenished by dust, volcanic eruptions, or floods can forests maintain themselves for time intervals longer than a few decades or centuries. Nutrient inputs from outside appear to be critical to the long-term maintenance of many if not most ecosystems, much as trade is essential for the health of the human economy (see also Polis et al. 1997).

Unsustainable use of resources is thus more evident in the human economy than in other living systems, thanks to a burgeoning population and rising per-capita 
consumption (Cohen 1995; Penn 2003); but it is not unique to it. This fact does not absolve us from the responsibility to protect the systems that provide the resources and services on which we and the rest of the living world depend (Arrow et al. 1995). In the past, we could import food and fuel from outside sources to support a growing economy, but we have reached the point where few if any resources remain outside our economic reach (Wackernagel et al. 2002). This monopoly of the biosphere carries with it all the perils familiar to economists and political scientists who study concentration of power in business and society.

\section{Implications}

I have tried to show that all ten differences between human and nonhuman economies are matters of degree rather than radical departures of humans from the natural order. Our traits confer unprecedented power and reach; they have accelerated but not fundamentally altered trends toward greater power that have characterized life (and especially its ecologically dominant elements) throughout Earth's long history. Our innovations have lifted previous constraints on the number of adaptive pathways available, on the speed of adaptive response, and on the range of conditions under which life can thrive, much as evolutionary innovations have done for life in the past.

No matter how advanced our future civilization will become, it will retain properties that all living systems possess, and it is unlikely to escape entirely from the constraints inherent in resource-dependent life. Economic policies and visions of the future must take these realities into account. We cannot eliminate local competition, voluntarily reduce energy use, avoid resource limitation, or sacrifice redundancy in favor of economic efficiency.

\subsection{Local competition}

Despite a globalized economy in which goods, labor, and capital flow more freely across borders than ever, and in which supply chains span the globe, local competition remains a vital process. In discussing clusters of businesses engaged in similar economic pursuits in restricted geographic areas, Porter (1998, p. 78) noted that 'the enduring competitive advantages in a global economy lie increasingly in local things-knowledge, relationships, motivation — that distant rivals cannot match.' He might have added resources to his list of 'local things', but the point remains the same: competition within and among these geographic clusters of companies engaged in related fields is local, intense, and necessary for maintaining and enhancing economic performance, measured in our growth-oriented economy as productivity. Cooperation among members of clusters, among cities, and among societies may eliminate competition at one level, but it creates more vigorous competitors at more inclusive levels of organization and is itself driven by local competition (Vermeij 2004). Moreover, local competition between potentially dominant entities favors winners whose traits confer greater power and reach, and losers that either avoid competition or are constrained to live under conditions where their enemies operate less effectively. Only during crises in resource availability will the more powerful entities suffer a disadvantage. 
Living systems, including our own, will therefore always have characteristics imposed by local competition reflecting the activities and performance of their most powerful members. Schemes to prevent competition are against nature and are doomed to fail (Vermeij 2004; see also Rothschild 1990).

\subsection{Reduced energy use}

A common perception of the future is that our reliance on material things and energy will decline as dependence on information rises. Sterrer (1992), for example, argues that the accumulation of information about sources and sinks of energy should generally be favored in evolution over the accumulation of energy itself, because information is destroyed when its owner dies, whereas energy is transferable and therefore invites robbery. I agree that adaptive information accumulates in both the human and the nonhuman realms of life; but accumulation of energy remains important, because living things need energy to do the work of life and to exert power, which is the criterion by which adaptive and economic performance is measured. In the same vein as Sterrer's claim, Ayres (1994, p. 287) asserts that 'while it operates somewhat erratically, there does seem to be a long-range evolutionary imperative favoring low-energy and renewable technologies for the future industrial ecosystem, as in the biosphere.' I agree that more energy will come from renewable sources, and that a clade's long geological lifespan is very often associated with a low-energy mode of life; but ecologically dominant clades are composed of high-energy life-forms, and show no signs of reduced energy use as long as they retain their positions. A decline in our future use of energy even as we consolidate our economic dominance and continue to grow would therefore reverse billions of years of evolution of wave after wave of ecologically elite forms of life. Human history has thus far not departed from the trend toward rising energy use (Cohen 1995; Landes 1998; Vermeij 2004). Voluntary reductions in energy use or power are unknown either in human history (Colinvaux 1980) or the history of life (Vermeij 2004). When reductions do occur, they are imposed by unforeseen catastrophes-famines, droughts, wars, mass extinctions, and the like — or by newly arrived superior competitors.

\subsection{Resource limitation}

Some economists claim that natural resources no longer limit economic growth. Instead, technological innovation and institutional adaptability determine the pace of growth in the modern human economy. Snooks (1998, p. 197), for example, maintains that 'The force constraining the expansion and growth of human society is not the supply of resources, but the exhaustion of its dynamic strategies and the inability to replace them with new strategies.' Rothschild's (1990) position is similar: 'Ecosystems are "resource-limited" networks.-By contrast, an industry's size is limited by consumer demand, not the availability of resources' (Rothschild 1990, p. 214). Further, he claims (p. 280) that 'the capitalist system, like the ecosystem itself, spontaneously reduces its dependence on scarce and expensive resources.' Echoing much recent sentiment among economists and politicians, Rothschild (p. 336) maintains 
that 'In a world of fixed resources, learning allows the economic pie to keep growing. Economic growth is limited only by human creativity.'

These claims are founded on erroneous interpretations and uncritical ideology. For example, Rothschild's assertion that industry is limited by customers rather than by resources is at odds with the universally acknowledged importance of investment in permitting industries to grow. Investment, which is equivalent to energy, is therefore a limiting resource for industry. Moreover, demand and supply are intimately linked and cannot be functionally separated. Flowering plants are like industries in depending on 'customers' (pollinators in their case), but in order to attract those customers, they must expend considerable energy in the form of nectar in much the same way that businesses must expend resources to attract buyers for their goods and services.

Even if industry were limited by demand rather than by supply, as Rothschild and many others claim, many individuals and groups within society are unambiguously constrained by scarce financial resources. Yet Rothschild, like other free-market economists, abhors taxes as a means of redistributing wealth and easing the resource inequalities inherent in a competitive system. By taking money from the rich, so the argument goes, there is less money available for investment. Moreover-and this is Rothschild's main justification - taxes and the governments that levy them are unknown in the economies of nature.

This justification is again based on a misreading of the facts in the forest and the realities on the reef. Ants defend plants against insects, and pollinators perform services of cross-fertilization for plants, for a high price, a tax of living space, of nectar, or food bodies. These taxes may not be levied by a top-down government, but the effect is the same: a redistribution of resources. Ecosystems and human societies all redistribute production, and although they vary in the degree to which this is accomplished by diffuse, bottom-up means or concentrated, top-down, government-like entities, the effect is to allow a greater diversity of economic players to coexist. Resource limitation is by no means removed by this kind of resource redistribution, but community-wide limitation is diffused among a greater number of individuals much as the risk of financial catastrophe is spread by the institution of insurance.

It is true that long-term economic growth has occurred in the history of life and in the human economy thanks to innovations that confer greater power and that permit the extraction of energy from previously untapped sources (Vermeij 2004). However, although some depleted resources such as wood and petroleum can be replaced by others (Perlin 1989), this option is less available for human food. Production of food has thus far kept up with human-economic growth both because new foodstuffs have been added to the diet and because crop yields have increased (Landes 1998), but the rate at which crop yields are improving in rice and other major staples is declining even with the application of biotechnology and breeding programs that favor plants with short stature and large inflorescences (Denison et al. 2003). Cultivated land is being lost to soil erosion and salinization as well as to industry and urbanization worldwide (Hillel 1991; Wackernagel et al. 2002), and marine resources are being severely overexploited (Worm et al. 2006). Humans are therefore globally mining biological sources of food (Wackernagel et al. 2002). Processes by which essential elements are being recycled and the chemistry of the ocean and atmosphere is maintained are being disrupted, potentially reducing the biosphere's productive capacity and other functions on which 
our existence critically depends (Arrow et al. 1995). In other words, it is dangerous and misleading to assert that finite resources can support a perpetually growing economy.

Finally, I emphasize an important distinction between global scarcity, which affects population size and economic complexity, and the scarcity that limits individual living entities. Sunlight is not a limiting resource for the world's vegetation taken as a whole, because only about $1 \%$ of sunlight is captured by photosynthesis; but when one plant is shaded by another, light becomes a locally limiting resource. Competition for light has been a critically important factor in the evolution of plant stature and architecture (Horn 1971; Vermeij 2004). Thus even if global resource limitation is eased by technological advances or by government, competitive interactions over locally contested resources remain fundamental economic determinants for involved parties and their descendants.

\subsection{Economic concentration}

One of the foundations of modern economics, the principle of comparative advantage, is being embraced by free-trade enthusiasts to support a policy of concentrating production and other vital economic activities to a few centers dedicated to those functions. According to this principle, regions that can produce a given commodity most cheaply or most efficiently should be those in which that production is concentrated; subsidies supporting production elsewhere should, according to this perspective, be abandoned because they distort the market.

Such policies of concentration are both risky and inconsistent with lessons from the economies of nature. Concentration reduces the safety factor in food production and ecosystem services. A global catastrophe could engulf society if a regional crop failure, disease, or war disrupts production in the region of concentration, or if the transport system on which the global distribution of goods depends suffers a breakdown through a sudden rise in cost. Officials knowledgeable about trade policy with whom I have discussed this matter had ignored these perils of concentration in their zeal to purge the global economy of 'protectionist' measures. Biological systems for billions of years have been characterized by redundancy, which spreads risks and enables systems of loosely linked but still interdependent parts to absorb and recover from shocks. Disruptions are inevitable — their history is as old as life itself_-but policy-makers can limit their destructive power by building redundancy into the production and distribution of goods, even at the cost of reduced efficiency. Redundancy may be at odds with economic efficiency, but in the long run it is better to have a safety net of redundant production than to be efficient and dead.

\section{Concluding remarks}

Comparative economics may appear to be an academic discipline of little practical consequence, but perceptions about the human economy as being either radically different from or sharing fundamental similarities with the economies of life embody important assumptions that in turn inform our worldview of the future. Those who consider civilization as a radical departure from nature follow a long tradition of 
thinking about human-economic progress as a struggle against nature, a conflict that increasingly frees us from constraints and that allows us to transcend or even violate the laws of the rest of the biosphere. Those who see the human realm as an extreme variation on a common theme of life hold that some economic phenomena are universal, and that violation of the principles underlying these phenomena would be disastrous. I clearly belong in this second camp, but I leave the last word to Jacobs (2000, p. 31): "economic development is a matter of using the same universal principles that the rest of nature uses. The alternative isn't to develop some other way; some other way doesn't exist.'

Acknowledgement I thank Janice Cooper for invaluable technical assistance, and Janet Landa for pointing me to some important papers.

Open Access This article is distributed under the terms of the Creative Commons Attribution Noncommercial License which permits any noncommercial use, distribution, and reproduction in any medium, provided the original author(s) and source are credited.

\section{References}

Agrawal, A. A. (2001). Phenotypic plasticity in the interactions and evolution of species. Science, 294, 321326.

Aiello, L. C., \& Wells, J. C. K. (2002). Energetics and the evolution of the genus Homo. Annual Review of Anthropology, 31, 323-338.

Ambrose, S. H. (2001). Paleolithic technology and human evolution. Science, 291, 1748-1753.

Arrow, K., Bolin, B., Costanza, R., Dasgupta, P., Folke, C., Holling, C. S., Jansson, B.-O., Levin, S., Mäler, K.-G., Perrings, C., \& Pimentel, D. (1995). Economic growth, carrying capacity, and the environment. Science, 268, 520-521.

Arthur, W. B. (1989). Competing technologies, increasing returns, and lock-in by historical events. Economic Journal, 99, 116-131.

Arthur, W. B. (1999). Complexity and the economy. Science, 284, 107-109.

Ayres, R. U. (1994). Information, entropy, and progress. New York: American Institute of Physics.

Bateman, R. M., \& DiMichele, W. A. (1994). Heterospory: The most iterative key innovation in the evolutionary history of the plant kingdom. Biological Reviews, 69, 345-417.

Becker, G. S. (1976). The economic approach to human behavior. Chicago: University of Chicago Press.

Bowles, S., \& Hammerstein, P. (2003). Does market theory apply to biology?. In P. Hammerstein (Ed.), Genetic and cultural evolution of cooperation (pp. 151-165). Cambridge, MA: MIT Press.

Boyden, S. (1987). Western civilization in biological perspective: Patterns in biohistory. Oxford: Clarendon.

Bramble, D. M., \& Lieberman, D. E. (2004). Endurance running and the evolution of Homo. Nature, 432, 345-352.

Brooks, D. R., Collier, J., Maurer, B. A., Smith, J. D. H., \& Wiley, E. O. (1989). Entropy and information in evolving biological systems. Biology and Philosophy, 4, 407-432.

Brown, J. H. (1995). Macroecology. Chicago: University of Chicago Press.

Buss, L. W. (1987). The evolution of individuality. Princeton: Princeton University Press.

Butler, A. B., \& Cotterill, R. M. J. (2006). Mammalian and avian neuroanatomy and the question of consciousness in birds. Biological Bulletin, 211, 106-127.

Carey, J. R., \& Judge, D. S. (2001). Lifespan in humans is self-reinforcing: A general theory of longevity. Population and Development, 7, 411-436.

Carroll, S. B. (2005). Endless forms most beautiful: The new science of evo devo and the making of the animal kingdom. New York: W. W. Norton.

Cassill, D. L. (2006). Why skew selection, a model of parental exploitation. Journal of Bioeconomics, $8,101-119$. 
Castro, L., \& Toro, M. A. (2004). The evolution of culture: From primate social learning to human culture. Proceedings of the National Academy of Sciences, 101, 10235-10240.

Chaisson, E. J. (2001). Cosmic evolution: The rise of complexity in nature. Cambridge, MA: Harvard University Press.

Chaisson, E. J. (2005). Epic of evolution: Seven ages of the cosmos. New York: Columbia University Press.

Chen, I. A. (2006). The emergence of cells during the origin of life. Science, 314, 1558-1559.

Cohen, J. E. (1995). How many people can the Earth support?. New York: W. W. Norton.

Colinvaux, P. (1980). The fates of nations: A biological theory of history. New York: Simon and Schuster.

Conway Morris, S. (2003). Life's solution: Inevitable humans in a lonely universe. Cambridge, UK: Cambridge University Press.

Corning, P. A. (2005). Holistic Darwinism: Synergy, cybernetics, and the bioeconomics of evolution. Chicago: University of Chicago Press.

Danchin, E., Giraldeau, L.-A., Valone, T. J., \& Wagner, R. H. (2004). Public information: From nosy neighbors to cultural evolution. Science, 305, 487-491.

Darwin, C. (1859). On the origin of species by natural selection, or the preservation of favoured races in the struggle for life. London: John Murray.

de Duve, C. (2005). Singularities: Landmarks on the pathways of life. Cambridge, UK: Cambridge University Press.

Denison, R. F., Kiers, E. T., \& West, S. A. (2003). Darwinian agriculture: When can humans find solutions beyond the reach of natural selection?. Quarterly Review of Biology, 78, 145-168.

Dennett, D. C. (1995). Darwin's dangerous idea: Evolution and the meaning of life. New York: Simon and Schuster.

Denny, M. W. (1993). Air and water: The biology and physics of life's media. Princeton: Princeton University Press.

de Soto, H. (2000). The mystery of capital: Why capitalism triumphs in the West and fails everywhere else. New York: Basic.

de Waal, F. B. M. (1996). Good natured: The origins of right and wrong in humans and other animals. Cambridge, MA: Harvard University Press.

de Waal, F. B. M. (2001). The ape and the sushi master: Cultural reflections of a primatologist. New York: Basic.

Diamond, J. (1997). Guns, germs, and steel: The fate of human societies. New York: W. W. Norton.

Diamond, J. (2005). Collapse: How societies choose to fail or succeed. New York: Viking.

Doolittle, W. F., \& Bapteste, E. (2007). Pattern pluralism and the Tree of Life hypothesis. Proceedings of the National Academy of Sciences, 204, 2043-2049.

Dudley, R. (2000). The biomechanics of insect flight: Form, function, evolution. Princeton: Princeton University Press.

Eigen, M. (with R. Winkler-Oswatitsch). (1992). Steps toward life: A perspective on evolution. Oxford: Oxford University Press.

Eldredge, N. (1985). Unfinished synthesis: Biological hierarchies and modern evolutionary thought. New York: Oxford University Press.

Fehr, E. (2004). Don't lose your reputation. Nature, 432, 449-450.

Fehr, E., \& Fischbacher, U. (2003). The nature of human altruism. Nature, 425, 785-791.

Finch, C. E., \& Crimmins, E. M. (2004). Imflammatory exposure and historical changes in human life-spans. Science, 305, 1736-1739.

Fischer, A. G. (1984). Biological innovations and the sedimentary record. In H. D. Holland \& A. F. Trendall (Eds.), Patterns of change in Earth evolution (pp. 145-157). Berlin: Springer.

Fogel, R. W. (1994). Economic growth, population theory, and physiology: The bearing of long-term processes on the making of economic policy. American Economic Review, 84, 369-395.

Fontana, W., \& Buss, L. W. (1994). What would be conserved if "the tape were played twice"?. Proceedings of the National Academy of Sciences, 91, 757-761.

Foster, J. (2005). The self-organizational perspective on economic evolution: A unifying paradigm. In K. Dopfer (Ed.), The evolutionary foundations of economics (pp. 367-390). Cambridge, UK: Cambridge University Press.

Frank, S. A. (1996). The design of natural and artificial adaptive systems. In M. R. Rose \& G. V. Lauder (Eds.), Adaptation (pp. 451-505). San Diego: Academic Press. 
Ghabrial, A. S., \& Karsnow, M. A. (2006). Social interactions among epithelial cells during tracheal branching morphogenesis. Nature, 441, 746-749.

Goddard, M. R., Godfray, H. C. J., \& Burt, A. (2005). Sex increases the efficacy of natural selection in experimental yeast populations. Nature, 434, 636-640.

Gould, S. J. (2002). The structure of evolutionary theory. Cambridge: Belknap Press of Harvard University.

Greene, B. (2004). The fabric of the cosmos: Space, time, and the texture of reality. New York: Knopf.

Hauert, C., Traulsen, A., Nowak, M. A., \& Sigmund, K. (2007). Via freedom to coercion: The emergence of costly punishment. Science, 316, 1905-1907.

Henrich, J., McElreath, R., Barr, A., Ensminger, J., Barrett, C., Bolyanatz, A., Cardenas, J. C., Gurven, M., Gwako, E., Henrich, N., Lesorogol, C., Marlowe, F., Tracer, D., \& Ziker, J. (2006). Costly punishment across human societies. Science, 312, 1767-1770.

Hillel, D. (1991). Out of the Earth: Civilization and the life of the soil. Berkeley: University of California Press.

Hirshleifer, J. (1977). Economics from a biological viewpoint. Journal of Law and Economics, 20, 1-52.

Hodgson, G. M. (1999). Economics and utopia: Why the learning economy is not the end of history. London: Routledge.

Hodgson, G. M. (2001). How economics forgot history: The problem of historical specificity in social science. London: Routledge.

Hodgson, G. M. (2002). Darwinism in economics: From analogy to ontology. Journal of Evolutionary Economics, 12, 259-281.

Horn, H. S. (1971). The adaptive geometry of trees. Princeton: Princeton University Press.

Jablonski, N. G. (2004). The evolution of human skin and skin color. Annual Review of Anthropology, 33, 585-623.

Jacobs, J. (2000). The nature of economics. New York: Random House.

Kaplan, B. S., \& Robson, A. J. (2002). The emergence of humans: The coevolution of intelligence and longevity with intergenerational transfers. Proceedings of the National Academy of Sciences, 99, 10221-10226.

Kauffman, S. A. (1993). The origins of order: Self-organization and selection in evolution. New York: Oxford University Press.

Kauffman, S. A. (2000). Investigations. Oxford: Oxford University Press.

Keller, E. F. (2007). A clash of two cultures. Nature, 445, 603.

Keller, L., \& Genoud, M. (1997). Extraordinary lifespans in ants: A test of evolutionary theories of aging. Nature, 389, 958-960.

Kiers, E. T., Rousseau, R. A., West, S. A., \& Denison, R. F. (2003). Host sanctions and the legumeRhizobium mutualism. Nature, 425, 78-81.

Kirschner, M., \& Gerhart, J. (1998). Evolvability. Proceedings of the National Academy of Sciences, 95, 8420-8427.

Kirschner, M. W., \& Gerhart, J. C. (2005). The plausibility of life: Resolving Darwin's dilemma. New Haven: Yale University Press.

Kornacker, K. (1968). Towards a physical theory of self-organization. In C. H. Waddington (Ed.), Towards a theoretical biology (Vol. 1, pp. 94-95). Chicago: Aldine.

Krugman, P. (1996). The self-organizing economy. Cambridge, MA: Blackwell.

Landa, J. T. (1976). An exchange economy with legally binding contracts: A public choice approach. Journal of Economic Issues, 10, 905-922.

Landa, J. T. (1981). A theory of the ethnically homogeneous middleman group: An institutional alternative to contract law. Journal of Legal Studies, 10, 349-362.

Landa, J. T. (1998). Bioeconomics of schooling fishes: Selfish fish, quasi-free riders, and other fishy tales. Environmental Biology of Fishes, 53, 353-364.

Landa, J. T. (1999). The law and bioeconomics of ethnic cooperation and conflict in plural societies of southeast Asia: A theory of Chinese merchant success. Journal of Bioeconomics, 1, 269-284.

Landa, J. T. (2008) The bioeconomics of homogeneous middleman groups as adaptive units: Theory and empirical evidence viewed from a group selection framework. Journal of Bioeconomics, 10(3), 259-278 (Special Issue, 'Group Selection: Theory and evidence', J. T. Landa \& D. S. Wilson (Eds.)).

Landes, D. S. (1998). The wealth and poverty of nations: Why some are so rich and some so poor. New York: W. W. Norton. 
Langergraber, K. E., Mitani, J. C., \& Vigilant, L. (2007). The limited impact of kinship on cooperation in wild chimpanzees. Proceedings of the National Academy of Sciences, 104, 7786-7790.

Leigh, E. G., Jr. (1983). When does the good of the group override the advantage of the individual?. Proceedings of the National Academy of Sciences, 80, 2985-2989.

Leigh, E. G., Jr., \& Rowell, T. E. (1995). The evolution of mutualism and other forms of harmony at various levels of biological organization. Ecologie, 26, 131-152.

Leigh, E. G., Jr., \& Vermeij, G. J. (2002). Does natural selection organize ecosystems for the maintenance of high productivity and diversity?. Philosophical Transactions of the Royal Society of London, B357, 709-718.

Lindert, P. H. (2004). Growing public: Social spending and economic growth since the eighteenth century. Volume I: The story. Cambridge, UK: Cambridge University Press.

Lotka, A. J. (1922). Contribution to the energetics of evolution. Proceedings of the National Academy of Sciences, 8, 147-151.

Lynch, M. (2007). The frailty of adaptive hypotheses for the origins of organismal complexity. Proceedings of the National Academy of Sciences, 104(1), 8597-8604.

Mallet, J. (2007). Hybrid speciation. Nature, 446, 279-283.

Marden, J. H., \& Allen, R. L. (2002). Molecules, muscles, and machines: Universal performance characteristics of motors. Proceedings of the National Academy of Sciences, 99, 4161-4166.

Margulis, L. (1991). Symbiogenesis and symbionticism. In L. Margulis \& R. Fester (Eds.), Symbiosis as a source of evolutionary innovation: Speciation and morphogenesis (pp. 1-14). Cambridge, MA: MIT Press.

Martin, W., \& Russell, M. J. (2003). On the origins of cells: A hypothesis for the evolutionary transitions from abiotic geochemistry to chemoautotrophic prokaryotes, and from prokaryotes to nucleated cells. Philosophical Transactions of the Royal Society of London, B358, 59-85.

Maynard Smith, J. (1991). A Darwinian view of symbiosis. In L. Margulis \& R. Fester (Eds.), Symbiosis as a source of evolutionary innovation: Speciation and morphogenesiss (pp. 26-39). Cambridge, MA: MIT Press.

Mesoudi, A., Whiten, A., \& Lalande, K. N. (2004). Is human cultural evolution Darwinian? Evidence reviewed from the perspective of The Origin of Species. Evolution, 58, 1-11.

Milinski, M., Semmann, D., \& Krambeck, H.-J. (2002). Reputation helps solve the "tragedy of the commons". Nature, 415, 424-426.

Mithen, S. (2006). The singing Neanderthals: The origins of music, language, mind and body. Cambridge, MA: Harvard University Press.

Mokyr, J. (1990). The lever of riches: Technological creativity and economic progress. New York: Oxford University Press.

Mokyr, J. (2002). The gifts of Athena: Historical origins of the knowledge economy. Princeton: Princeton University Press.

Mokyr, J. (2006). Economics and the biologists: A review of Geerat J. Vermeij's Nature: An Economic History. Journal of Economic Perspectives, 44, 1005-1013.

Monod, J. (1971). Chance and necessity: An essay on the natural philosophy of modern biology. New York: Knopf.

Morowitz, H. J. (1968). Energy flow in biology: Biological organization as a problem in thermal physics. New York: Academic Press.

Newman, S. A., \& Müller, G. B. (2001). Ontogenetic mechanisms for character origination. In G. P. Wagner (Ed.), The character concept in evolutionary biology (pp. 559-579). San Diego: Academic Press.

Nisbet, E. G., \& Sleep, N. H. (2001). The habitat and nature of early life. Nature, 409, 1083-1091.

Noë, R., \& Hammerstein, P. (1996). Biological markets. Trends in Ecology and Evolution, 19, 336-339.

North, D. C. (2005). Understanding the process of economic change. Princeton: Princeton University Press.

Nowak, M. A. (2006). Five rules for the evolution of cooperation. Science, 314, 1560-1563.

Ofek, H. (2001). Second nature: Economic origins of human evolution. Cambridge, UK: Cambridge University Press.

Palmer, A. R. (2004). Symmetry breaking and the evolution of development. Science, 306, 828-833.

Panchanathan, K., \& Boyd, R. (2004). Indirect reciprocity can stabilize cooperation without the second-order free rider problem. Nature, 432, 499-502.

Penn, D. J. (2003). The evolutionary roots of our environmental problems: Toward a Darwinian ecology. Quarterly Review of Biology, 78, 275-301. 
Perlin, J. (1989). A forest journey: The role of wood in the development of civilization. Cambridge, MA: Harvard University Press.

Pigliucci, M. (2001). Characters and environments. In G. P. Wagner (Ed.), The character concept in evolutionary biology (pp. 363-388). San Diego: Academic Press.

Polis, G. A., Anderson, W. B., \& Holt, R. D. (1997). Toward an integration of landscape and food web ecologies: The dynamics of spatially subsidized food webs. Annual Review of Ecology and Systematics, 28, 289-316.

Popper, K. R. (1964). The poverty of historicism (4th ed.). New York: Harper and Row.

Porter, M. E. (1998, November-December). Clusters and the new economics of competition. Harvard Business Review, 77-90

Pryor, F. L. (2003). What does it mean to be human? A comparison of primate economies. Journal of Bioeconomics, 5, 97-146.

Raby, C. R., Alexis, D. M., Dickinson, A., \& Clayton, N. S. (2007). Planning for the future by Western scrub-jays. Nature, 445, 919-923.

Raff, R. A. (1996). The shape of life: Genes, development, and the evolution of animal form. Chicago: University of Chicago Press.

Renseleers, T., \& Ratnieks, F. L. (2006). Enforced altruism in insect societies. Nature, 444, 50.

Ricklefs, R. E. (1979). Adaptation, constraint, and compromise in avian postnatal development. Biological Reviews, 54, 269-290.

Reid, R. G. B. (2007). Biological emergences: Evolution by natural experiment. Cambridge, MA: MIT Press.

Riedl, R. (1978). Order in living organisms. New York: Wiley.

Rietkerk, M., Dekker, S. C., Ruiter, P. C., \& van de Koppel, J. (2004). Self-organized patchiness and catastrophic shifts in ecosystems. Science, 305, 1926-1929.

Rosen, S. P. (2005). War and human nature. Princeton: Princeton University Press.

Rosing, M. T., Bird, D. K., Sleep, N. H., Glassley, W., \& Albarede, F. (2006). The rise of continentsan essay on the geologic consequences of photosynthesis. Palaeogeography, Palaeclimatology, Palaeoecology, 232, 99-113.

Rothschild, M. (1990). Bionomics: The inevitability of capitalism. New York: Henry Holt.

Seabright, P. (2004). The company of strangers: A natural history of economic life. Princeton: Princeton University Press.

Seilacher, A. (1991). Self-organizing mechanisms in morphogenesis and evolution. In N. Schmidt-Kittler (Ed.), Constructional morphology and evolution (pp. 251-271). Berlin: Springer.

Smith, A. (1776). An inquiry into the nature and causes of the wealth of nations. London: Strahan and Cadell.

Snooks, G. D. (1998). The laws of history. London: Routledge.

Sober, E., \& Wilson, D. S. (1998). Unto others: The evolution and psychology of unselfish behavior. Cambridge, MA: Harvard University Press.

Stanley, S. M. (1975). A theory of evolution above the species level. Proceedings of the National Academy of Sciences, 72, 646-650.

Sterrer, W. (1992). Prometheus and Proteus: The creative, unpredictable individual in evolution. Evolution and Cognition, 1, 101-129.

Sterrer, W. (1993). Human economics: A non-human perspective. Ecological Economics, 7, $183-202$.

Thompson, D. W. (1942). On growth and form. London: Cambridge University Press.

Thompson, J. N., \& Cunningham, B. M. (2002). Geographic structure and dynamics of coevolutionary selection. Nature, 417, 735-738.

Tschirhart, J. (2003). Ecological transfers in non-human communities parallel economic markets in a general equilibrium ecosystem model. Journal of Bioeconomics, 5, 193-214.

Turner, J. S. (2006). The tinkerer's accomplice: How design emerges from life itself. Cambridge, MA: Harvard University Press.

Van Valen, L. (1976). Energy and evolution. Evolutionary Theory, 1, 179-229.

Vermeij, G. J. (1999). Inequality and the directionality of history. American Naturalist, 153, $243-253$.

Vermeij, G. J. (2002). Characters in context: Molluscan shells and the forces that mold them. Paleobiology, 28, 41-54.

Vermeij, G. J. (2004). Nature: An economic history. Princeton: Princeton University Press.

Vermeij, G. J. (2005). From phenomenology to first principles: Toward a theory of diversity. Proceedings of the California Academy of Sciences, 56(Supplement I, number 2), 12-23. 
Vermeij, G. J. (2006). Historical contingency and the purported uniqueness of evolutionary innovations. Proceedings of the National Academy of Sciences, 103, 1804-1809.

Vetsigian, K., Woese, C., \& Goldenfeld, N. (2006). Collective evolution and the genetic code. Proceedings of the National Academy of Sciences, 103, 10696-10701.

Wackernagel, M., Schulz, N. B., Deumling, D., Callejas Linares, A., Jenkins, M., Kapos, V., Monfreda, C., Loh, J., Myers, N., Norgaard, R., \& Randers, J. (2002). Tracking the ecological overshot of the human economy. Proceedings of the National Academy of Sciences, 99, 9266-9271.

Waddington, C. H. (1962). New patterns in genetics and development. New York: Columbia University Press.

Wardle, D. A., Walker, L. R., \& Bardgett, R. D. (2004). Ecosystem properties and forest decline in contrasting long-term chronosequences. Science, 305, 509-513.

Weaver, A. H. (2005). Reciprocal evolution of the cerebellum and neocortex in fossil humans. Proceedings of the National Academy of Sciences, 102, 3576-3580.

Weber, B. H., Depew, D. J., Dyke, C., Salthe, S. N., Schneider, E. D., Ulanowicz, R. E., \& Wicken, J. S. (1989). Evolution in thermodynamic perspective: An ecological approach. Biology and Philosophy, 4, 373-405.

West-Eberhard, M. J. (1983). Sexual selection, social competition, and speciation. Quarterly Review of Biology, 58, 155-183.

Westoby, M., \& Rice, B. (1982). Evolution of the seed plants and inclusive fitness of plant tissues. Evolution, 36, 713-724.

Wiley, E. O., \& Brooks, D. R. (1982). Victims of history-a nonequilibrium approach to evolution. Systematic Zoology, 31, 1-24.

Williams, G. C. (1966). Adaptation and natural selection: A critique of some current evolutionary thought. Princeton: Princeton University Press.

Wilson, A. C., Sarich, V. M., \& Maxson, L. R. (1974). The importance of gene rearrangement in evolution: Evidence from studies on rates of chromosomal, protein, and anatomical evolution. Proceedings of the National Academy of Sciences, 71, 3028-3030.

Wilson, D. S. (1974). A theory of group selection. Proceedings of the National Academy of Sciences, 72, 143-146.

Wilson, D. S. (2002). Darwin's cathedral: Evolution, religion, and the nature of society. Chicago: University of Chicago Press.

Wilson, D. S. (2003). Conceptual frameworks for thinking about primate economies: Comments on Pryor's paper. Journal of Bioeconomics, 5, 147-148.

Wilson, E. O. (1971). The insect societies. Cambridge, MA: Belknap Press of Harvard University.

Wilson, E. O., \& Hölldobler, B. (2005). Eusociality: Origin and consequences. Proceedings of the National Academy of Sciences, 102, 13367-13371.

Woese, C. (1998). The universal common ancestor. Proceedings of the National Academy of Sciences, 95, 6854-6859.

Worm, B., Barbier, E. B., Beaumont, N., Duffy, J. E., Folke, C., Halpern, B. S., Jackson, J. B. C., Lotze, H. K., Micheli, F., Palumbi, S. R., Sala, E., Selkoe, K. A., Stachowicz, J. J. \& Watson, R. (2006). Impacts of biodiversity loss on ocean ecosystem services. Science, 314, 787-790. 